\title{
KEBUTUHAN DAYA PADA AIR CONDITIONER SAAT TERJADI PERBEDAAN SUHU DAN KELEMBABAN
}

\author{
Sri Indarwati ${ }^{1}$, Sri Mulyo Bondan Respati ${ }^{2^{*}}$ dan Darmanto ${ }^{2}$ \\ ${ }^{1}$ Mahasiswa Jurusan Teknik Mesin Fakultas Teknik Universitas Wahid Hasyim \\ ${ }^{2}$ Jurusan Teknik Mesin Fakultas Teknik Universitas Wahid Hasyim \\ Jl. Menoreh Tengah X/22 Sampangan Semarang \\ *E-mail: bondan@unwahas.acid
}

\begin{abstract}
ABSTRAK
AC atau Air Conditioner adalah menyerap udara dari bagian luar. Dan melepaskan udara di bagian outdoor, dari ini udara indoor yang telah dihasilkan akan berangsur-angur berkonverter sehingga dapat membuat ruangan menjadi suhu yang dingin .Suhu adalah besaran yang menyatakan derajat panas dingin suatu benda dan alat yang digunakan untuk mengukur suhu adalah termometer. Kelembaban merupakan suatu tingkat keadaan lingkungan udara basah yang disebabkan oleh adanya uap air. Tingkat kejenuhan sangat dipengaruhi oleh temperatur. Jika tekanan uap parsial sama dengan tekanan uap air yang jenuh maka akan terjadi pemadatan. Secara matematis kelembaban relative $(R H)$ didefinisikan sebagai prosentase perbandingan antara tekanan uap air parsial dengan tekanan uap air jenuh. Kelembaban dapat diartikan dalam beberapa cara. Relative Humidity secara umum mampu mewakili pengertian kelembaban. Untuk mengerti Relative Humidity pertama harus diketahui Absolut Humidity. Absolut Humidity merupakan jumlah uap air pada volume udara tertentu yang dipengaruhi oleh temperatur dan tekanan.

Metode penelitian menggunakan deskriptif kualitatif-kuantitatif atau penelitian terapan yang di dalamnya mencangkup penelitian survey. Alat penelitian menggunakan : AC, Termometer, Hygrometer, Multimeter atau multitester, dan Clamp Meter / Tang Ampere. Sedangkan bahan penelitian menggunakan udara, udara sendiri adalah campuran gas yang terdapat pada lapisan yang mengelilingi bumi. Jenis data penelitian yaitu data primer. Metode pengumpulan data diambil dari studi observasi lapangan dan kepustakaan.

Hasil penelitian diketahui Semakin rendah suhu yang diinginkan dalam ruangan, maka kinerja Air Conditioner akan semakin tinggi dan Semakin tinggi kelembaban dalam ruangan, maka kinerja Air Conditioner akan semakin tinggi.
\end{abstract}

Kata kunci: suhu, kelembaban, kinerja, air conditioner

\section{Pendahuluan}

AC atau Air Conditioner adalah menyerap udara dari bagian luar. Dan melepaskan udara di bagian outdoor, dari ini udara indoor yang telah dihasilkan akan berangsur-angur berkonverter

sehingga dapat membuat ruangan menjadi suhu yang dingin. Secara lumrah AC adalah alat perabot rumah tangga yang bersifat elektronik yang memiliki unsur sirkulasi udara oleh blower indoor melewati sirip

Evaporator. Setelah melewati evaporato rudara yang panas akan diserap oleh bahan pendingin dan udara dingin yang kita rasakan adalah sirkulasi udara dari Blower Outdoor sampai Blower indoor. Sistem AC hanyalah sirkulasi udara dan panas akan diserap oleh bahan pendingin yakni Refrigerant (Freon). Air Coniditioner (AC) pada dewasa ini semakin banyak digunakan dan dimanfaatkan seiring dengan kemajuan teknologi dan taraf hidup. Penggunaan umum seperti mengawetkan bahan makanan, pada suhu biasa (suhu kamar) makanan cepat menjadi busuk karena pada temperatur biasa bakteri akan berkembang lebih cepat. Sedangkan pada suhu $4,4{ }^{\circ} \mathrm{C}$ atau $40{ }^{\circ} \mathrm{F}$ (suhu yang biasa untuk pendinginan makanan), bakteri berkembang sangat lambat sehingga makanan akan lebih tahan lama.

Cara kerja Air Conditioner yaitu kompresor yang ada pada sistem pendingin dipergunakan sebagai alat untuk memampatkan fluida(refrigerant), jadi refrigerant yang masuk ke dalam kompresor dialirkan ke kondensor yang kemudian dimampatkan di kondensor. Di bagian kondensor ini refrigerant yang dimampatkan akan berubah fase dari refrigerant fase uap menjadi refrigerant fase cair, maka refrigerant mengeluarkan kalor yaitu kalor penguapan yang terkandung di dalam refrigerant. (Dirja, 2004, Berman, 2013) 
Suhu adalah besaran yang menyatakan derajat panas dingin suatu benda dan alat yang digunakan untuk mengukur suhu adalah termometer. Dalam kehidupan sehari-hari masyarakat untuk mengukur suhu cenderung menggunakan indera peraba. Tetapi dengan adanya perkembangan teknologi maka diciptakanlah termometer untuk mengukur suhu dengan valid. (Hidayati, 2011)

Kelembaban merupakan suatu tingkat keadaan lingkungan udara basah yang disebabkan oleh adanya uap air. Tingkat kejenuhan sangat dipengaruhi oleh temperatur. Jika tekanan uap parsial sama dengan tekanan uap air yang jenuh maka akan terjadi pemadatan. Secara matematis kelembaban relative $(\mathrm{RH})$ didefinisikan sebagai prosentase perbandingan antara tekanan uap air parsial dengan tekanan uap air jenuh. Kelembaban dapat diartikan dalam beberapa cara. Relative Humidity secara umum mampu mewakili pengertian kelembaban. (Lagiyono, 2012)

Dari latar belakang tersebut dapat dilihat bahwa kebutuhan daya AC, apakah terpengaruh oleh suhu dan kelembaban dari luar. Tujuan dari penelitian ini untuk mengetahui kebutuhan daya AC yang dipengaruhi oleh suhu dan kelembaban

\section{METODE PENELITIAN}

Jenis penelitian ini bersifat deskriptif kualitatif-kuantitatif atau penelitian terapan yang di dalamnya mencangkup penelitian survey, dimana penelitian dengan pendekatan kualitatif dalam penelitiaan ini yaitu penelitian non matematis dengan proses menghasilkan data-data dari hasil temuan berupa pengamatan survey. Adapun penelitian kuantitatif dalam penelitian ini yaitu jenis penelitan dengan menggunakan data-data subtansi atau angka sebagai bahan perbandingan maupun bahan rujukan dalam menganalisis secara deskriptif.

\section{Alat dan Bahan Penelitian}

\section{Alat Penelitian}

a. Air Conditioner

AC atau Air Conditioner adalah menyerap udara dari bagian luar dan melepaskan udara di bagian outdoor dari ini udara indoor yang telah dihasilkan akan berangsur-angur berkonverter sehingga dapat membuat ruangan menjadi suhu yang dingin.

b. Termometer
Termometer adalah alat yang digunakan untuk mengukur suhu (temperatur), ataupun perubahan suhu. Istilah termometer berasal dari bahasa Latin thermo yang berarti panas dan meter yang berarti untuk mengukur.

\section{c. Hygrometer}

Hygrometer berasal dari bahasa Yunani yaitu hugros yang berarti lembab dan metreo berarti mengukur. Hygrometer merupakan alat untuk mengukur kelembaban udara. Sedang thermohygro adalah sebuah alat untuk mengukur suhu udara dan kelembaban, baik di dalam ruangan ataupun di luar ruangan.

d. Multimeter atau multitester

Multimeter atau multitester adalah alat pengukur listrik yang sering dikenal sebagai AVO meter (Ampere-Volt-Ohm meter) yang dapat mengukur tegangan (voltmeter), hambatan (ohm-meter), maupun arus (amperemeter).

e. Clamp Meter / Tang Ampere

Clamp meter adalah sebuah alat ukur yang sangat nyaman digunakan yang memberikan kemudahan pengukuran arus listrik tanpa mengganggu rangkaian listriknya.

\section{Bahan Penelitian}

Udara adalah campuran gas yang terdapat pada lapisan yang mengelilingi bumi. Komponen yang konsentrasinya paling bervariasi yaitu uap air dan $\mathrm{CO} 2$, kegiatan yang berpotensi menaikkan konsentrasi CO2 seperti pembusukan sampah tanaman, pembakaran atau sekumpulan massa manusia di dalam ruangan terbatas yaitu karena proses pernapasan (Lagiyono, 2012).

\section{Jenis dan Sumber Data}

Jenis data yang digunakan dalam penelitian ini, yaitu data primer. Data primer yaitu data yang berasal langsung dari sumber data yang dikumpulkan secara khusus dan berhubungan langsung dengan permasalahan yang diteliti. Sumber data primer pada penelitian ini diperoleh langsung dari hasil penelitian mengenai kinerja air conditioner.

\section{Metode Pengumpulan Data}

a. Studi observasi lapangan

b. Kepustakaan 
HASIL DAN PEMBAHASAN

1. Hasil Penelitian

Data dari hasil pengukuran umtama yaitu suhu dan kelembaban ruangan yang telah diolah, maka menghasilkan parameterparameter data hasil kajian dan pengukuran ditunjukan sebagai berikut :

Tabel 1. Data Pengambilan Suhu dan Kelembaban

\begin{tabular}{|c|c|c|c|c|c|c|c|}
\hline \multirow[b]{2}{*}{ Tanggal } & \multirow[b]{2}{*}{ Jam } & \multicolumn{2}{|c|}{ Dalam Ruang } & \multicolumn{2}{|c|}{ Luar Ruang } & \multirow[b]{2}{*}{$\begin{array}{c}\text { Arus } \\
\text { Listrik } \\
\text { (ampere) }\end{array}$} & \multirow[b]{2}{*}{$\begin{array}{l}\text { Tegangan } \\
\text { (Voltage) }\end{array}$} \\
\hline & & $\begin{array}{l}\text { Suhu } \\
\left({ }^{\circ} \mathrm{C}\right)\end{array}$ & $\begin{array}{c}\text { Kelembab } \\
\text { an } \\
(\%)\end{array}$ & $\begin{array}{l}\text { Suhu } \\
\left({ }^{\circ} \mathrm{C}\right)\end{array}$ & $\begin{array}{c}\text { Kelem } \\
\text { baban } \\
(\%)\end{array}$ & & \\
\hline \multirow{4}{*}{$\begin{array}{l}21 \text { Maret } \\
2018\end{array}$} & 01.00 & 27 & 81 & 27,4 & 82 & 2,2 & 203 \\
\hline & 05.00 & 25,4 & 74 & 26,1 & 79 & 1,9 & 200 \\
\hline & 14.00 & 27,9 & 81 & 29,5 & 76 & 1,8 & 205 \\
\hline & 18.00 & 27,5 & 77 & 28,2 & 78 & 2 & 198 \\
\hline \multirow{4}{*}{$\begin{array}{l}22 \text { Maret } \\
2018\end{array}$} & 01.00 & 26,2 & 77 & 26,3 & 78 & 1,8 & 214 \\
\hline & 05.00 & 25 & 73 & 25,4 & 78 & 1,6 & 210 \\
\hline & 14.00 & 26,5 & 83 & 27,3 & 84 & 2,1 & 200 \\
\hline & 18.00 & 26,2 & 76 & 26,9 & 78 & 2,1 & 204 \\
\hline \multirow{4}{*}{$\begin{array}{l}23 \text { Maret } \\
2018\end{array}$} & 01.00 & 25.2 & 75 & 25,8 & 79 & 2,0 & 210 \\
\hline & 05.00 & 24,2 & 74 & 25 & 80 & 1,8 & 208 \\
\hline & 14.00 & 25,8 & 76 & 26,9 & 79 & 2,2 & 202 \\
\hline & 18.00 & 26,3 & 75 & 27,2 & 83 & 2,1 & 203 \\
\hline \multirow{4}{*}{$\begin{array}{l}24 \text { Maret } \\
2018\end{array}$} & 01.00 & 25 & 75 & 25,8 & 81 & 1,9 & 207 \\
\hline & 05.00 & 24,3 & 75 & 25,4 & 81 & 1,9 & 208 \\
\hline & 14.00 & 26,1 & 77 & 27 & 79 & 1,8 & 201 \\
\hline & 18.00 & 25,9 & 81 & 27,1 & 83 & 2,0 & 203 \\
\hline \multirow{4}{*}{$\begin{array}{l}25 \text { Maret } \\
2018\end{array}$} & 01.00 & 25,2 & 77 & 25,8 & 82 & 1,9 & 211 \\
\hline & 05.00 & 24,9 & 79 & 25,4 & 83 & 1,8 & 209 \\
\hline & 14.00 & 26,8 & 82 & 27,2 & 84 & 1,9 & 208 \\
\hline & 18.00 & 25,8 & 84 & 26,1 & 84 & 2,0 & 203 \\
\hline \multirow{4}{*}{$\begin{array}{l}26 \text { Maret } \\
2018\end{array}$} & 01.00 & 24,2 & 76 & 24,9 & 82 & 1,8 & 214 \\
\hline & 05.00 & 23,6 & 76 & 24,3 & 81 & 1,8 & 209 \\
\hline & 14.00 & 26,4 & 83 & 27,1 & 84 & 1,9 & 210 \\
\hline & 18.00 & 26,2 & 82 & 26,8 & 84 & 1,8 & 219 \\
\hline \multirow{4}{*}{$\begin{array}{l}27 \text { Maret } \\
2018\end{array}$} & 01.00 & 25,5 & 83 & 26,1 & 84 & 1,8 & 210 \\
\hline & 05.00 & 25,3 & 83 & 25,6 & 84 & 1,8 & 208 \\
\hline & 14.00 & 26 & 81 & 26,2 & 83 & 1,9 & 206 \\
\hline & 18.00 & 25,9 & 80 & 26 & 82 & 1,9 & 209 \\
\hline
\end{tabular}

a. Pengaruh Suhu Terhadap Kienrja Air Conditioner

Hasil dari statistik uji-t digunakan untuk menguji hipotesis ada tidaknya pengaruh suhu terhadap kinerja AC kapasitas 1 PK pada ruang kamar.

Untuk mengetahui pengaruh suhu terhadap kinerja Air Conditioner dapat dilihat dari grafik Gambar 1:

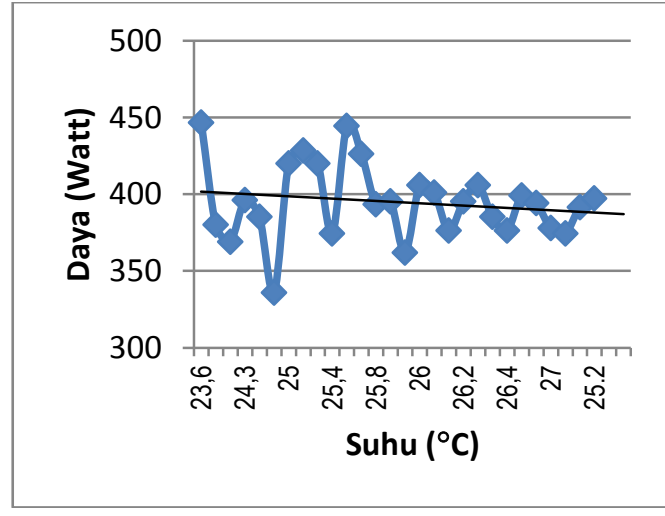

Gambar 1 Suhu terhadap Daya 
Berdasarkan grafik Gambar 1 dapat disimpulkan bahwa dengan melihat dari tabel perhitungan tabel 4.1. dengan penelitian yang diambil pada tanggal 21 Maret 2018 sampai dengan 27 Maret 2018 diketahui bila suhunya rendah dalam ruangan maka semakin tinggi kinerja Air Conditioner..

\section{b. Pengaruh Kelembaban Terhadap Kinerja Air Conditioner}

Bahwa kelembaban di dalam ruangan menunjukkan $81 \%$ dan di luar ruangan menunjukkan sebesar $82 \%$ dengan daya yang diperlukan air conditioner yaitu 2,2A/203V. Dalam hal ini menunjukkan bahwa kelembaban berpengaruh positif terhadap kinerja air conditioner.

Untuk mengetahui pengaruh kelembaban terhadap kinerja Air Conditioner dapat dilihat dari grafik Gambar 2:

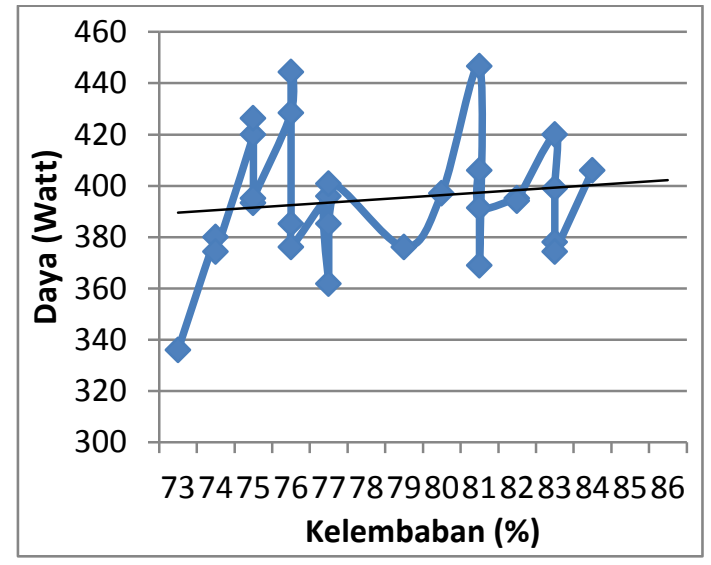

\section{Gambar 2. Kelembaban terhadap Daya}

Berdasarkan grafik di Gambar 2 dapat disimpulkan bahwa dengan melihat dari tabel perhitungan tabel 4.1. dengan penelitian yang diambil pada tanggal 21 Maret 2018 sampai dengan 27 Maret 2018 diketahui semakin tinggi kelembaban dalam ruangan maka meningkat pula kinerja Air Conditioner.

\section{Pembahasan}

\section{a. Pengaruh Suhu Terhadap Kinerja Air Conditioner}

Berdasarkan hasil pengujian hipotesis 1 menjelaskan bahwa suhu berpengaruh positif terhadap kinerja air conditioner, artinya bila semakin tinggi suhu ruangan yang masuk ke dalam ruangan, maka akan semakin menurunnya kinerja air conditioner. Hasil dari statistik uji-t digunakan untuk menguji hipotesis ada tidaknya pengaruh suhu terhadap kinerja AC kapasitas 1 PK pada ruang kamar.. Artinya ada pengaruh yang signifikan antara suhu terhadap kinerja AC kapasitas 1 PK pada ruang kamar.

Kondisi iklim atau udara luar merupakan faktor yang berpengaruh besar terhadap kinerja unit pengkondisian udara. Oleh karena itu, perhitungan kondisi udara menjadi sangat penting agar unit pengkondisian udara bekerja efektif.Hal ini menunjukkan bahwa temperatur atau suhu dapat mempengaruhi kinerja Air Conditioner, karena bila suhunya rendah maka kinerja air conditioner semakin tinggi.

\section{b. Pengaruh Kelembaban Terhadap Kinerja Air Conditioner}

Berdasarkan hasil pengujian hipotesis 2 menjelaskan bahwa kelembaban berpengaruh positif terhadap kinerja air conitioner, artinya bila menurunnya kinerja air conitioner, maka akan semakin tinggi kelembaban di dalam ruangan.

Kelembaban udara pada ruangan ber-AC umumnya lebih rendah dari pada udara tanpa AC. Pada dasarnya AC berfungsi mendinginkan udara, untuk lebih spesfiknya di bagian evaporator AC (bagian indoor). Udara dialirkan melalui evaporator sehingga mengalami pendinginan. Udara yang dialirkan ini memiliki kandungan uap air. Udara akan menuju titik embun jika terus didinginkan. Titik embun adalah kondisi dimana udara tidak dapat menampung uap air, sehingga uap air mengembun menjadi tetesan air. Pada evaporator ini udara mengalami pengembunan, oleh karenanya sering kali kita lihat ada kondensat (air) dialirkan melalui saluran (selang) dari bagian indoor AC. Setelah melewati evaporator, udara dingin ini dialirkan kembali keruangan. Ini artinya terjadi pengurangan jumlah uap air yang ada diudara pada saat melewati evaporator, akibatnya udara menjadi lebih kering.

\section{KESIMPULAN}

Dari hasil analisis data maka dapat disimpulkan:

1. Semakin rendah suhu yang diinginkan dalam ruangan, maka kinerja air conditioner akan semakin tinggi.

2. Semakin tinggi kelembaban dalam ruangan, maka kinerja air conditioner akan semakin tinggi. 


\section{Saran}

Penulis berharap pada penelitian selanjutnya dapat memperhitungkan beberapa faktor yang berpengaruh pada kinerja air conditioner yaitu dimensi dan volume ruangan serta beban pendingin seperti jumlah penghuni dan penggunaan penerangan.

\section{DAFTAR PUSTAKA}

Berman, E.T. 2013. Modul PLPG : Teknik Pendingin. Jakarta : Konsorsium Sertifikasi Guru

Dirja. 2004. Dasar-Dasar Mesin Pendingin. Jakarta : Departemen Pendidikan Nasional Direktorat Jenderal Pendidikan Dasar dan Menengah Direktorat Pendidikan Menengah Kejuruan

Hidayati, Putri. 2011. Pengaruh setting temperatur terhadap kinerja ac Split. Jurnal Teknik Konversi Energi

Lagiyono. 2012. Pengaruh udara masuk terhadap suhu air conditioner (ac) kapasitas 1 pk pada ruang instalasi uji. Jurnal Fakultas Teknik Universitas Negeri Semarang.

http://projectmedias.blogspot.co.id/2014/01/jen is-dan-macam-macam-ac.html 